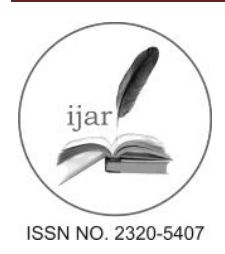

Journal homepage: http://www.journalijar.com
Journal DOI: 10.21474/IJAR01

RESEARCH ARTICLE

\title{
CORRELATION OF HIGHER MATERNAL BLOOD SUGAR LEVELS WITH NEONATAL BIRTH WEIGHT IN NON-DIABETIC PREGNANT MOTHERS.
}

\author{
Dr. Mahek Mukhi ${ }^{1}$, Dr. Vandana. R. Nimbargi ${ }^{2}$, Dr. Savita. S. Mehendale ${ }^{3}$. \\ 1. Resident, Dept. Ob/Gyn, BVDUMC, Pune. \\ 2. Professor, Dept. Ob/Gyn, BVDUMC,Pune. \\ 3. Professor, Dept. Ob/Gyn, BVDUMC, Pune.
}

\section{Manuscript Info}

Manuscript History:

Received: 10 February 2016

Final Accepted: 26 March 2016

Published Online: April 2016

Key words:

OGCT, Normoglycemia, Birth weight.

*Corresponding Author

Dr. Mahek Mukhi.

\begin{abstract}
Fetus and placenta depend on unique physiologic systems to provide an environment supporting fetal growth and development in preparation for transition to extra-uterine life.

Fetal growth depends on the maternal nutritional status. Glucose is the principal energy substrate for the placenta and the fetus. It is an essential requirement for normal fetal metabolism and growth. Glucose supply is derived via maternal carbohydrate metabolism and gluconeogenesis of amino acids.

Pregnant women with blood sugar levels in the higher range of normal are more likely to give birth to healthier babies. ${ }^{[1,2]}$

This study was conducted to correlate maternal OGCT values done thrice in the course of the pregnancy with fetal outcome in the form of birth weight. 300 antenatal patients were followed till delivery. It was observed that an increased maternal blood sugar level, within the normal range, was related to increased Neonatal Birth Weight in healthy mothers.
\end{abstract}

\section{Introduction:-}

Fetal growth depends on the maternal nutritional status. The fetus utilizes nutrients for two primary purposes: oxidation for energy and tissue accretion. For appropriate fetal growth there is need of adequate amount of glucose, amino acids, fatty acids and vitamins.

Glucose is the principal energy substrate for the placenta and the fetus. It is an essential requirement for normal fetal metabolism and growth. Glucose supply is derived via maternal carbohydrate metabolism and gluconeogenesis of amino acids. The main regulators of glucose transport between the mother and the fetus are glucose transporter proteins in the placenta. These transporters, members of the GLUT gene family of facilitated-diffusion transporters, are embedded in the microvillus (maternal-facing) and basal (fetal-facing) membranes of the syncytiotrophoblast, the main placental barrier layer. However, only GLUT-1 protein has been identified in the syncytium. GLUT-1 is up-regulated during gestation, increased in diabetic pregnancy and decreased in chronic hypoxia leading to IUGR. $[3,4]$

Saleh $\mathbf{J}$ et al. investigated the association of maternal parameters of healthy non-diabetic mothers with Neonatal Birth Weight of their "appropriate-for-gestational age" neonates. Post-load glucose levels were significantly higher in mothers of heavier neonates. ANOVA results indicated that $15 \%$ increase in post-load glucose levels corresponded to more than $0.5 \mathrm{Kg}$ increase in neonatal birth weight (NBW) in the third percentile. This study highlighted that increased maternal post-load sugar levels and blood pressure, within thenormal range, highly predicts NBW of healthymothers. These findings may provide focus for early dietary intervention measures to avoid future risks to the mother and baby ${ }^{[5]}$. 
The present study was conducted with the aim of co-relating the maternal blood sugar levels with weight of newborns in normoglycemic pregnant mothers.

\section{Material and methods:-}

A hospital based observational study of 300 antenatal patients was conducted at Bharati Hospital, Pune over a period of 2 years. OGCT values were done thrice during pregnancy: $1^{\text {st }}$ at $14-16$ weeks, $2^{\text {nd }}$ at $22-28$ weeks, $3^{\text {rd }}$ at $32-34$ weeks. The subjects were then categorised according to OGCT values into 2 groups: 70-95mg/dl and 96-120mg/dl. Patients were then followed till delivery to know the pregnancy outcome and birth weight of babies. Qualitative data was presented as frequency and percentage and analyzed using chi-square test. P-value of $<0.05$ was considered as significant.

\section{Observation and results:-}

Table 1: Distribution based on Oral Glucose Challenge Test (OGCT)

\begin{tabular}{|l|l|l|l|}
\hline OGCT $(\mathbf{m g \%})$ & Mean & SD & p- value \\
\cline { 1 - 3 } $\mathbf{1 4 - 1 6}$ weeks & 86.51 & 12.47 & \multirow{2}{*}{$\mathbf{0 . 0 1}$} \\
\cline { 1 - 3 } $\mathbf{2 2 - 2 8}$ weeks & 95.23 & 12.09 & \\
\hline $\mathbf{3 2 - 3 4}$ weeks & 93.52 & 14.80 & $\mathbf{0 . 4 2}$ \\
\hline
\end{tabular}

Mean Oral Glucose Challenge Test (OGCT) values increased significantly between 14-16 weeks and 22-28 weeks (86.5 vs $95.2 \mathrm{mg} \%$; $\mathrm{p}<0.05$ ) but stabilizes thereafter at 32-34 weeks ( $\mathrm{p}>0.05$ ).

Table 2:Comparison of Birth weight based on OGCT group

\begin{tabular}{|l|l|l|l|l|l|}
\hline Variable & OGCT Group & N & Mean & SD & p- value \\
\hline Birth Weight (Kg) & $\mathbf{7 0 - 9 5 ~} \mathbf{~ m g \%}$ & 194 & 2.75 & 0.24 & $<\mathbf{0 . 0 1}$ \\
\cline { 2 - 6 } & $\mathbf{9 6 - 1 2 0 ~} \mathbf{~ m g \%}$ & 106 & 3.05 & 0.35 & \\
\hline
\end{tabular}

Mean weight of babies of high normal OGCT group was significantly more compared to low normal group (3.05 vs $2.75 \mathrm{Kg} ; \mathrm{p}<0.05)$.

Table 3: Co-relation between birth weight and OGCT values

\begin{tabular}{|l|l|l|}
\hline Pearson's Co-relation & r-value & p-value \\
\hline Mean OGCT Vs Birth Weight & 0.3 & $<0.05$ \\
\hline
\end{tabular}

A significant positive co-relation was observed between birth weight and blood sugar levels of mother ( $\mathrm{r}-0.3$; $\mathrm{p}<$ 0.05

Table 4. Comparison of Anthropometric parameters of Mothers based on OGCT group

\begin{tabular}{|c|c|c|c|c|c|}
\hline Variable & OGCT Group & $\mathbf{N}$ & Mean & SD & p- value \\
\hline \multirow{2}{*}{ Mean Age (years) } & $70-95$ mg\% & 194 & 24.20 & 3.39 & \multirow{2}{*}{0.15} \\
\hline & 96-120 mg\% & 106 & 22.90 & 3.11 & \\
\hline \multirow[t]{2}{*}{ Height (cm) } & 70-95 mg\% & 194 & 156.48 & 7.19 & \multirow[t]{2}{*}{$<0.05$} \\
\hline & 96-120 mg\% & 106 & 151.95 & 6.41 & \\
\hline \multirow[t]{2}{*}{ Weight (Kg) } & 70-95 mg\% & 194 & 52.70 & 10.11 & \multirow[t]{2}{*}{0.96} \\
\hline & 96-120 mg\% & 106 & 52.84 & 9.56 & \\
\hline \multirow[t]{2}{*}{ BMI (Kg/m2) } & 70-95 mg\% & 194 & 21.50 & 3.52 & \multirow[t]{2}{*}{0.17} \\
\hline & 96-120 mg\% & 106 & 22.83 & 3.50 & \\
\hline
\end{tabular}

No significant difference was observed between Mean age, weight and BMI between OGCT groups. However mean height of mothers of low normal OGCT group was significantly more.

\section{Discussion and conclusion:-}

We observed that mean weight of babies of high normal OGCT group was significantly more compared to low normal group (3.05 vs $2.75 \mathrm{Kg}$; $\mathrm{p}<0.05)$. A significant positive co-relation was observed between birth weight and blood sugar levels of mother $(r-0.3 ; p<0.05)$.

The positive association between blood glucose and the risk of delivering large for gestational age (LGA) neonates was a common observation in several studies without adjustment for covariates ${ }^{[6-9]}$. 
As the $75 \mathrm{~g}$ OGCT can be regarded as a surrogate marker of meal postprandial glycaemia ${ }^{[10]}$, the findings of this study agree with previous findings in that mild elevations in glucose tolerance, or mild dietary glucose elevations within the normal range, may result in increased fetal growth ${ }^{[1]]}$.Patel VN et al. conducted a study on 93 pregnant women to monitor longitudinal changes in blood glucose levels in pregnancy and to co-relate it with various maternal and fetal outcomes. They observed that maternal postprandial blood glucose levels affect the birth weight of the baby and also mode of delivery ${ }^{[12]}$.

This study highlights that increases in maternal post-load sugar levels, within the normal range, highly predict the outcome of Neonatal Birth Weight in AGA neonates. This is particularly apparent in the results showing that increases in post-load glucose levels determine increases in Neonatal Birth Weight in the absence of maternal diabetes. The findings of this study support that estimation of maternal PP2 Blood Glucose levels (OGCT) should be carried out in all pregnant women at the first antenatal visit and at least once in every trimester. This would help to reduce adverse perinatal outcomes

\section{References:-}

1. Hollander, Martine H., K. Marieke Paarlberg, and Anjoke JM Huisjes. "Gestational diabetes: a review of the current literature and guidelines." Obstetrical \& gynecological survey 62.2 (2007): 125-136.

2. Robert Block. Mothers' High Normal Blood Sugar Levels Place Infants at Risk for Birth Problems. National Institute of Health, USA. 2008. Available at http://www.nih.gov/news/health/may2008/nichd-07.html

3. Baumann M, Deborde S, Illsley NP, "Placental glucose tranfer and fetal growth"Endocrine Vol19(1), Oct:1322,2002

4. Scholl T, Sowers M, Chen X, Am J of Epidemiol. Vol154(6),2001.

5. Saleh, Jumana, Lovina Machado, and Zahra Razvi. "2-Hour Postload Serum Glucose Levels and Maternal Blood Pressure as Independent Predictors of Birth Weight in "Appropriate for Gestational Age" Neonates in Healthy Nondiabetic Pregnancies." BioMed research international 2013 (2013).

6. M. Sermer, C. D. Naylor, D. J. Gare et al., "Impact of increasing carbohydrate intolerance on maternal-fetal outcomes in 3637 women without gestational diabetes," American Journal of Obstetrics and Gynecology, vol. 173, no. 1, pp. 146-156, 1995.

7. D. A. Sacks, J. S. Greenspoon, S. Abu-Fadil, H. M. Henry, G. Wolde-Tsadik, and J. F. Yao, "Toward universal criteria for gestational diabetes: the 75-gram glucose tolerance test in pregnancy," American Journal of Obstetrics and Gynecology, vol. 172, pp. 607-614, 1995.

8. L. Tallarigo, O. Giampietro, and G. Penno, "Relation of glucose tolerance to complications of pregnancy in nondiabetic women," The New England Journal of Medicine, vol. 315, no. 16, pp. 989-992, 1986.

9. R. R. Little, E. M. McKenzie, J. M. Shyken et al., "Lack of relationship between glucose tolerance and complications of pregnancy in nondiabetic women," Diabetes Care, vol. 13, no. 5, pp. 483-487, 1990.

10. J. C. Y. Louie, J. C. Brand-Miller, T. P. Markovic, G. P. Ross, and R. G. Moses, "Glycemic index and pregnancy: a systematic literature review," Journal of Nutrition and Metabolism, vol. 2010, Article ID 282464, 8 pages, 2010.

11. M. Bonomo, D. Corica, E. Mion et al., "Evaluating the therapeutic approach in pregnancies complicated by borderline glucose intolerance: a randomized clinical trial," Diabetic Medicine, vol. 22, no. 11, pp. 1536-1541, 2005.

12. Patel, Vaishali Nanranbhai, et al. "Maternal postprandial blood glucose levels and its relation with the pregnancy outcomes." International Journal of Biomedical and Advance Research 5.3 (2014): 174-177. 